Medicine in the Elderly

\title{
The efficiency and effectiveness of geriatric day hospitals
}

\author{
D. Zeeli and B. Isaacs
}

Department of Geriatric Medicine, University of Birmingham, Hayward Building, Selly Oak Hospital, Birmingham B29 6JD, UK.

\begin{abstract}
Summary: One hundred patients who were referred consecutively to two geriatric day hospitals were followed for 3 months, to determine the efficiency and effectiveness of day hospital management. Transport was highly efficient; only one in every 40 attendances failed because of transport. Selection of patients may have been less efficient, in that only half completed planned treatment. In most cases this was because of progression of the illness. Time at the day hospital was on the whole efficiently used, in that three-quarters of the time was devoted to programmed activities. The effectiveness of the day hospital was limited. In only about one-third of referred patients were the objectives set by the doctor attained. Likewise only one-third of patients felt that they had improved, and one-third of carers experienced relief of strain.
\end{abstract}

\section{Introduction}

Day hospitals are a universal feature of British district geriatric services. Their contribution has been stressed by many writers $^{1-7}$ and some attempts have been made to evaluate them. ${ }^{8-13}$

The objectives of geriatric day hospitals were defined by Brocklehurst and Tucker ${ }^{4}$ as medical and nursing care; rehabilitation; social and recreational; and relief of carers.

We studied the experiences of patients who attended two geriatric day hospitals in the West Midlands, in order to determine the efficiency and effectiveness of day hospital care. We defined 'efficient' as providing the service that was intended; and 'effective' as achieving the objectives that were set.

\section{Material and methods}

One hundred patients aged 60 and over were studied. They were referred consecutively by consultant physicians from the wards or after domiciliary or outpatient consultation to the day hospitals of two large urban geriatric services in the West Midlands. On referral the physician prescribed the frequency of attendance, which in almost all

\footnotetext{
Correspondence: Professor B. Isaacs, M.D., F.R.C.P.(Ed.), F.R.C.P(Glas.), F.R.C.P.(Lond.)

Accepted: 26 January 1988
}

patients was 2 days a week. The physician indicated $\overrightarrow{0}$ his major objective from the list proposed byo. Brocklehurst and Tucker. ${ }^{4}$ The patients and carers? indicated their major objectives in their own words, and these were then coded to comply as closely as possible with Brocklehurst's classification. Two weeks after the first attendance the staff likewise indicated their main objectives. Staff, patients and carers were also asked what they expected that the patient would be able to do at the conclusion of his attendance that he could not do at the commencement; and the answers were coded as 'improved mobility', 'other physical improvement', 'social, mental or behavioural improvement' or 'no change'. Carers were asked to say whether they anticipated experiencing relief of physical and mental strain as a result of the patient's attendance. After three months, or when the patient was discharged from attendance, the four groups were asked to what extent the objectives which they had set and the changes which they had anticipated were achieved.

The way in which patients spent their time in the day hospital was observed during 181 patient attendances. Every activity in which the patients were engaged was recorded on sheets for each minute of their stay at the day hospital. The activities were classified into 33 codes, grouped under four main headings, namely medical/nursing, rehabilitation, social/recreational and inactivity.

(C) The Fellowship of Postgraduate Medicine, 1988 
The codes for 'inactivity' were: waiting for ambulance; waiting for other activity; awake doing nothing; and asleep. The time spent in 'inactivity' was calculated for each attendance.

Waiting time at home was estimated from the patients' answers to the question, How long did you wait for the ambulance to arrive once you were dressed and ready? The time spent in travel to and from the day hospital was not directly observed, but was estimated by ambulance drivers to average 1 hour.

Four measures of efficiency were used, namely: loss of patients; loss of attendances; time spent doing nothing at the day hospital; and time spent waiting for transport at home.

Four measures of effectiveness were used, namely: attainment of the objectives set for attendance by doctors, staff, patients and carers.

\section{Results}

Of the 100 patients 38 were males and 62 females. Twenty-nine patients were under the age of 75,53 were aged between 75 and 84 , and 18 were aged 85 and over. Rehabilitation was defined as the major objective by doctors on initial referral in 84 patients; and at the commencement of treatment by staff in 60 cases, by 53 patients and by 57 carers. About 10 in each group identified medical/nursing as the main objective. Two doctors, four staff, one patient and three carers attached major importance to social and recreational needs; and three doctors, four staff, three carers, but no patients, looked on relief of carers as the principle objective of day hospital attendance. Nineteen patients and one carer did not know why they were attending.

\section{Efficiency}

Loss of patients Sixteen patients completed the prescribed course in less than 3 months, and a further 37 were still attending at the end of 3 months. Ten patients failed to start day hospital attendance because of death in five cases, hospitalization in three and refusal in two. Thirtyseven other patients were lost from attendance within 3 months of commencing because of death in three cases, hospitalization in 17 , refusal in 11 , moving away in three and other reasons in three.

Loss of attendances of 1146 planned attendances $168(15 \%)$ were lost, 28 of these $(2.5 \%)$ because of ambulance failures. The remainder were lost because the patients were unwell or did not wish to attend.
Inactivity During 181 attendances with an average duration of $5 \frac{1}{2} \mathrm{~h}$ the average time spent in inactivity was $95 \mathrm{~min}$. In all attendances the duration of inactivity was at least half an hour; in 46 between 1 and 2 hours; and in 16 more than 2 hours. Most of the inactivity time was while patients were waiting for the return ambulance.

Waiting at home The average time spent waiting at home dressed and ready for the ambulance to arrive was 60 minutes. Sixteen patients waited for an average of less than half an hour, 40 for between 1 and 2 hours and six for more than 2 hours.

Effectiveness The frequency with which the objectives set by the four groups on referral or at the commencement of treatment were considered to have been attained on discharge, or 3 months after commencing treatment, are given in Table I. The objectives of the doctors were fully achieved in 29 patients and partially achieved in a further 17 patients. The perceptions of the staff were similar. Rather fewer patients and carers stated that their objectives had been attained, more of these groups being 'unable to say'.

In Table II are set out the answers given by staff, patients and carers to the question whether hopedfor improvements had been achieved. Improved mobility was anticipated by staff in 47 cases, by? carers in 53 cases and by 36 patients; and was thought to have been achieved by 32 staff, 21 carers and 34 patients. The other objectives were achieved in similar proportions. The number of all groups who noted no improvement, though small, was approximately double the number who anticipated no improvement.

Sixty-five of 71 carers interviewed at the commencement of attendance anticipated reduction in strain. Among the 45 carers interviewed at the end of 3 months, 29 said that they had experienced relief of strain.

\section{Discussion}

The criticisms sometimes made of geriatric day

Table I Number of subjects assessed on discharge or after 3 months in whom the initial objectives were attained

\begin{tabular}{lccrc}
\hline Assessed by & Fully & Partially & Not & $\begin{array}{c}\text { Unable } \\
\text { to }\end{array}$ \\
\hline Doctor & 29 & 17 & 7 & 0 \\
Staff & 26 & 14 & 13 & 0 \\
Patient & 21 & 16 & 6 & 10 \\
Carer & 11 & 16 & 11 & 15 \\
\hline
\end{tabular}


Table II Comparison of expected and attained outcome in day hospital patients

\begin{tabular}{|c|c|c|}
\hline & Expected & Attained \\
\hline \multicolumn{3}{|l|}{ By staff } \\
\hline Improved mobility & 47 & 32 \\
\hline Other physical improvement & 7 & 5 \\
\hline Social, mental or behavioural & 9 & 3 \\
\hline No improvement & 7 & 13 \\
\hline Number of patients & 70 & 53 \\
\hline \multicolumn{3}{|l|}{ By patients } \\
\hline Improved mobility & 36 & 34 \\
\hline Other physical improvement & 2 & 3 \\
\hline Social, mental or behavioural & 7 & 6 \\
\hline No improvement & 2 & 6 \\
\hline Number of patients & 47 & 49 \\
\hline \multicolumn{3}{|l|}{ By carers } \\
\hline Improved mobility & 53 & 21 \\
\hline Other physical improvement & 3 & 1 \\
\hline Social, mental or behavioural & 9 & 5 \\
\hline No improvement & 6 & 11 \\
\hline Number of patients & 71 & 38 \\
\hline Less physical strain & 9 & 7 \\
\hline Less mental strain & 18 & 20 \\
\hline Less physical and mental strain & 38 & 2 \\
\hline No difference & 6 & 15 \\
\hline Number of carers & 71 & 44 \\
\hline
\end{tabular}

hospitals that ambulance services are unreliable, that patients wait for long periods at home, and that much of the time at day hospital is wasted are not fully borne out in this study. Ambulance failure caused only $2.5 \%$ of planned attendances to be lost, whereas medical factors caused the loss of $13 \%$. Waiting times at home were long, but exceeded 2 hours in only six people. Patients spent one-quarter of the time at day hospital doing nothing, but this mostly occurred at the end of an active programme during the unavoidable wait for the return ambulance.

The failure of 10 patients to commence treatment and of a further 37 to complete it according to plan is a more serious criticism of the efficiency of the day hospital. Most of these failures were due to rapid progression of the illness in a vulnerable population; but 13 of the 47 'losses' were due to patients or their carers refusing treatment. Similar losses were noted by others. Ramaiah and Jones ${ }^{13}$ 'lost' $60 \%$ of their day hospital patients by hospitalization or default; Pablo and Cleary ${ }^{14}$ lost $50 \%$; while Gilleard et al. ${ }^{10}$ reported a loss of $52 \%$ of psychogeriatric day hospital cases over an 8month period. Doctors referring patients to day hospital care should monitor losses of this type in the hope of improving selection of patients for day hospital attendance.

The measures of effectiveness used in this study were the reported perceptions of doctors, staff, patients and carers that the objectives they had set at the beginning of attendance were achieved; and that the expected benefits had been obtained. Those whose attendance was prematurely terminated were not assessed to determine whether any benefit had accrued from their abbreviated attendance, as it may well have done.

One-third of patients fully attained the goals which the doctors and staff had set; and nearly one-half of carers experienced the expected degree of relief of strain. More than one-third of patients who commenced attendance reported that they were able to do more things after day hospital attendance that they could not do before attendance. The validity of these judgements can be questioned, yet there was broad comparability of the perceptions of the different groups.

It is possible that expectations erred on the side of optimism. A function of day hospitals not included in Brocklehurst's list of objectives is to prevent the patient or the domestic situation getting worse; and many patients might justifiably have claimed that that was achieved.

Other studies of the benefits of day hospitak treatment have used a variety of methods, but have not evaluated the attainment of preset objectives.? Anand et al. ${ }^{9}$ concluded that $69 \%$ of their patients had benefited from day hospital attendance as measured by shortening of in-patient hospital stay; avoidance of or delay in admission to hospital; and reduction in use of hospital outpatient services. Bendall ${ }^{15}$ claimed that the day hospital reduced the number of patients seen on domiciliary visits who required admission to hospital; while Berry ${ }^{16}$ observed that closure of a day hospital led to an increase of hospital admissions. An opposite conclusion was reached by Greene and Timbury ${ }^{17}$ who felt that the opening of a psychogeriatric day hospital had increased the number of hospital admissions. Gilleard et al. ${ }^{10}$ used a structured questionnaire, a retrospective 7-day diary, scales of general health, strain, and social interaction, and a problem check list to study the benefits of psychogeriatric day hospital attendance to the carers of demented patients, and found that attendance was of value to the carers but not to the patients. Milne $^{12}$ used rating scales in a comparative study of two psychogeriatric day hospitals, and concluded that the benefits were due to the appropriateness of the treatment programme to the patients' needs.

Subjective assessments tend to show high levels of satisfaction with day hospital care. Patients may provide the answers that are wanted; or, as may 
have been the case in the present study, they may appreciate small improvements of function not recognized by others. Ramaiah and Jones ${ }^{13}$ assessed half of their patients as improved, onethird as unchanged and one-sixth as worse. Peach and Pathy $^{8}$ using a linear analogue self-assessment procedure, and Anand et al., ${ }^{9}$ using direct questions, reported satisfaction of patients with various aspects of their care. Benefit to carers was claimed by Anand et al. ${ }^{9}$ on direct questioning and by Jackson, ${ }^{11}$ who used psychological tests.

\section{Conclusion}

This study is based on a short period of experience in only two days hospitals. These pursued similar policies in referring severely disabled elderly patients from home or hospital mainly for rehabilitation. The ambulance service and the day hospital staffs were efficient; but there was heavy loss of patients because of progression of their illness. Objectives set for patients were not

\section{References}

1. Cosin, L. The place of the day hospital in the geriatric unit. Practitioner 1954, 172: 552-559.

2. Woodford-Williams, E., McKeon, J.A., Trotter, I.S., Watson, D. \& Busby, C. The day hospital in the community care of the elderly. Gerontologia Clinica 1969, 4: 241-256.

3. Brocklehurst, J.C. The Geriatric Day Hospital. King Edward's Hospital Fund for London, London, 1970.

4. Brocklehurst, J.C. \& Tucker, J.S. Progress in Geriatric Day Care. King Edward's Hospital Fund for London, London, 1980.

5. Fisher, R.H., Nadon, G.W., Dawson, P. \& CurrieMills, C. A geriatric day hospital: The Sunnybrook experience. Can Med Ass J 1981, 125: 447-450.

6. Hildick-Smith, M. Geriatric rehabilitation in day hospitals. Int Rehab Med 1985, 7: 120-124.

7. Vaughan, P.J. Developments in psychogeriatric day care. Br J Psychiat 1985, 147: 1-4.

8. Peach, H. \& Pathy, M.S. Evaluation of patients' assessment of day hospital care. Br J Prev Soc Med 1977, 31: 209-210.

9. Anand, K.B., Thomas, J.H., Osborne, K.L. \& Osmolski, R. Cost and effectiveness of a geriatric day hospital. J. Roy Coll Phys Lond 1982, 16: 53-56. always achieved, but patients appreciated small gains in function and carers experienced relief from care. The evaluation of outcome by questioning doctors, staff, patients and carers on the attainment of their objectives adds to the range of methods available for service evaluation in the field of day hospital care.

It is hoped that further studies will assist in the selection of patients, the setting of realistic objectives, and the monitoring of efficiency and effectiveness of geriatric day hospital care.

\section{Acknowledgements}

We express our thanks to the staffs of the two day hospitals, the ambulance crews and controllers, and the physicians for their cooperation and assistance in this study. We are especially grateful to the patients and their carers who answered our questions. Dr Zeeli was in receipt of the Charlotte Eyck Award from the British Medical Association, and was also supported by the Lewis Foundation.

10. Gilleard, C.J., Gilleard, E. \& Whittick, J.E. Impact of the psychogeriatric day hospital on the patient's family. Br J Psychiatry 1984, 145: 487-492.

11. Jackson, M.F. Day care for handicapped elders: an evaluation study. Can J Publ Hlth 1983, 74: 348-351.

12. Milne, D. A comparative evaluation of two psychiatric day hospitals. $\mathrm{Br} J$ Psychiatry 1984, 145: 533-537.

13. Ramaiah, R.S. \& Jones, D.T. Comparison of patients attending general practitioner and consultant day hospitals for the elderly. J Roy Coll Gen Pract 1984, 34: 505-508.

14. Pablo, R. \& Cleary, F. Parkwood day hospital: an alternative for the impaired elderly. Can J Publ Hlth 1982, 73: 176-182.

15. Bendall, M.J. Changing work patterns in a geriatric unit and the effect of a day hospital. Age \& Ageing 1976, 7: 229-232.

16. Berrey, P.N.E. Increase in acute admissions and deaths after closing a geriatric day hospital. $\mathrm{Br}$ Med $\mathrm{J}$ 1986, 292: 176-178.

17. Greene, J.G. \& Timbury, G.C. A geriatric psychiatry day hospital service: a five year reveiw. Age \& Ageing 1979, 8: 49-53. 